\title{
INTERCULTURAL METHODOLOGY IN SINOLOGY: TRANSCULTURALITY, TEXTUAL CRITICISM AND DISCURSIVE TRANSLATIONS
}

\author{
JANA S. ROŠKER
}

\begin{abstract}
For Western researchers, the understanding of Chinese culture is conditioned by differences in language, tradition, history and socialization. The interpretation of various aspects and elements of different cultures is always connected to the geographic, political and economic positions of the interpreter as well as the object of interpretation. In Western research on China, the non-reflected use of theoretical analyses that are in themselves results of specific (Western) historical processes and the related structure of societies, often proves to be a dangerous and misleading mechanism. A fundamental premise of the present paper is that Western epistemology represents only one of many different models of human comprehension of reality. On this basis, it questions traditional intercultural methodologies hitherto applied in Sinology and Chinese studies. The article presents the main methodological paradigms of a transculturally aware research that could improve the understanding of general principles underlying the particular research questions and objects under investigation.
\end{abstract}

Keywords: intercultural methodology; transcultural studies; China studies; Sinology; Orientalism

\section{Introduction: Intercultural and transcultural research}

Intercultural studies are always linked to questions about the relation between universality and particularity, between general valid principles which determine all human societies on the one hand, and specific features of cultural conditionality on the other. Although these general principles pertain to one and the same objective reality, their understanding can differ in different cultural and linguistic contexts. Therefore, different cultures produce different epistemologies, i.e. different views and expressions of the same actualities. In this respect, sinology is no exception. The methodology that is still commonly applied for studying traditional Chinese sources is hitherto still often based primarily on premises deriving from the traditional Western social sciences and humanities. If we want to find and apply transculturally aware, and more suitable methods, it is not enough to recognize that traditional Chinese sources are commonly embedded into 
a "different theoretical model." In addition, we have to locate our analyses into a framework which allows for a relativization of value systems and perception structures. Here, it is important to clarify that such a relativization of values does not imply that all values are equally good and reasonable or sensible. In other words, it does not imply that measurements that are not beneficiary for the universal well-being of humanity, or even in contradiction with preserving the integration and dignity of human beings, can be pursued and implemented in the name of some "specific culturally conditioned values". Thus, this kind of axiological relativization does not imply any principles of ethical relativism but should rather be understood as an overall instrument for preventing one-dimensional understandings of values, and thereby avoiding an absolute, general universalization of criteria for evaluating values by one single axiological discourse or one single axiological doctrine.

If we want to consider cultural differences, we need to gain insights into the conceptual structures and connections among the concrete historical, economic, political and philosophical systems that underlie Chinese social reality, shaping and modifying the complex entity commonly called Chinese culture. The awareness of these underlying rudiments - which also unavoidably influence the elementary theoretical approaches, methods and conceptual frameworks - constitute a platform which might enable us to gain a better understanding of traditional (but to a certain extent also modern) Chinese texts at their most profound levels.

In this context we should clarify the nature of our approach to reading Chinese sources. Since this paper is written mainly for Western readers, it automatically deals with its subject through the lens of cultural differences. When reading Chinese texts, readers born, educated and socialized in Western languages and social environments are confronted with different epistemologies, different perspectives, perceptions and patterns of knowledge acquisition and transmission. To a certain extent, and especially when it comes to ancient and traditional sources, this problem also affects today's Chinese readers who live in a globalized world where the standards of conception and understanding have been adopted from Western cultures.

Therefore, our approach to researching Chinese culture is intercultural in the sense of interaction and engagement of several cultures. Interculturality is a specific type of interaction or communication between discourses, where differences in cultures play a role in the formation of meaning. Intercultural interactions therefore involve the process of transferring meanings between cultures (Ongun 2016). However, many contemporary scholars (e.g. Welsch 1999) criticize such approaches claiming that the concept of interculturality starts from a conception of cultures as "islands" or "spheres" and creates a separatist character of cultures. In today's globalized world it is therefore important to understand that cultural factors have become transcultural. The transcultural understanding of cultures offers us a multi-perspective and inclusive rather than an exclusive and isolated approach (Ongun 2016). Transcultural research is a long-standing discourse, but with constantly changing and evolving paradigms. For at least half a century it has been an important field of theoretical investigation, which began with Eduardo Valera's construction of its methodological foundations (Valera 1972a; 1972b) and has developed more or less continuously in the following decades, also regarding research in Chinese theories, 
cultures and societies (see e.g. Fredericks 1988; Nielsen 1995; Siegel 1999; Heubel 2011; 2014; Lee 2013; Dai 2020 and many others).

The prefix "trans-" in the term "transcultural" suggests transcending not only one's borders, one's limits, while enriching, updating oneself. It suggests also the possibility to step beyond the very fragmentation and separateness of various cultures and philosophies (Silius 2020, 275).

Transcultural approaches therefore aim at overcoming the outdated, static and immobile concept of culture. This does not mean, however, that there is no culture. It is still a real thing, like language, for example. Both are dynamic, historically grown and constantly changing entities without fixed borders. Therefore, the ontological assumption underlying the concept of culture does not necessarily refer to a metaphysics of an abstract substantial being. In this context, the concept of culture is understood to be based on a metaphysics of relations. In this sense, I continue to use the two terms, i.e. both intercultural and transcultural: although it is impossible to draw firm and constant boundaries between them because they form a complex and often overlapping web of meaning, I use the former when referring to concrete interactions between different cultures $^{1}$ and their various elements, and the latter when referring to the goal and results of such interactions, i.e. to see oneself in the other.

To enable such a reflection in our investigation of the theoretical and methodological framework of Chinese studies and their formal, semantic and conceptual foundations, we must first take a closer look at some of the external elements that also strongly influence our interpretation and the modes of our understanding. These external elements are linked to the historically evolved epistemological structures of power relations.

\section{Orientalism and Reversed Orientalism}

In the context of the present study, it has first to be clarified that the terms "East" and "West," which are commonly denoting vast multicultural areas in Asia and within the so-called Euro-American cultural tradition respectively, are somewhat problematic, for they are based on generalized and essentialist views of areas covering multifaceted pallets of different historical, political and cultural developments. ${ }^{2}$ Usually, such characterizations are based upon a superficial view, according to which developmental traits of different cultures are fixed and predetermined; such views completely (and arrogantly) disregard the importance of variations among particular social, ideational and axiological developments within various cultures, belonging to these two umbrella categories.

Eric Nelson $(2020,249)$ even believes that concept of the "intercultural" is better described as the interaction of lifeworlds instead of cultures.

2 Besides, these terms as such are by no means value free; notions like the Middle- or the Far-East express the degree of distance from the "Center," which is geographically located in the "West." 
Bearing this in mind, I will in the framework of the present paper - for the sake of practicability - nonetheless apply the terms "Western" and "Chinese". However, they have to be understood as expressions, which do not exclusively refer to a certain geopolitical area (i.e. China vs. Europe, America, Australia and New Zealand), but are rather based upon the prevailing and distinct differentia specifica that profoundly marks the dominant currents in their respective theoretical development, namely the demarcation line between immanent and transcendent metaphysics.

In this context, we must also bear in mind that traditional sinology as an academic discipline was constituted within the scope of Orientalism, which - among other factors laid the foundations and conditions of the colonialist approach to the study of cultures which are not the fruit of the so called "Western" tradition. This is why the criticism of elements of Orientalism in sinology is simultaneously the criticism of the violent nature of the classical relation between knowledge and authority or knowledge and power.

In his famous book on Orientalism, Edward Said has defined the concept as "a style of thought based upon an ontological and epistemological distinction made between 'the Orient' and (most of the time) 'the Occident"' (Said 1978, 2).

In the Orientalist framework, the ideal of European identity was seen as a superior one in contrast to all non-European cultures and their people (ibid., 7). This alleged "superiority," however, has to be viewed in the context of the existing global economic (and consequently also political), power relations. Hence, Orientalism is a discourse or a framework of reference, which is inherently connected to "Western" institutions of power. Therefore, it is not enough to try and overcome it by simply affirming the "Orient" or the "East" over the "Occident" or the "West." This is because the "Orient" or the "East" can never be a free subject of thought or action, simply because in itself, it is a creation of the West (Hahm 2000, 103). Besides, it is completely clear that affirming one pole of the binary oppositional pair does not imply to overcome the dichotomy as such. ${ }^{3}$ The sensible thing to do would then be striving to find a completely independent epistemological position. However, this desire to get "outside", to establish an "objective" bird-eyes view is itself a typically Western ideal at least since Plato (ibid.). Hence, in the post-modern era, many intercultural discourses were based upon a presumption that it is impossible to surpass the boundaries of the semantic and axiological frameworks to which we are bound through our native languages and socio-cultural education. Thus, the post-modern approach of deconstructing various expressions and representations of reality can never be complete. As Chaibong $\operatorname{Hahm}(2000,103)$ points out, deconstruction is different from destruction precisely because it cannot "wipe the slates clean of Western prejudices."

Moreover, we cannot forget that all histories of ideas and all cultural discourses are ethnocentric. In an un-reflected ethnocentric view, one's own people "historically stand for civilization and its achievements, whereas the otherness of the others is a deviation from these standards" (Rüssen 2004, 62-63). In this sense, Eurocentrism as an either formally

\footnotetext{
However, this does by no means diminish the fact that was described as a phenomenon of "delinking" by Amin Samir. This notion is tightly linked to the fact that the privileged pole of the dichotomy can and will never freely give up its advantaged position. Chaibomg Hahm formulates this in the following way: "The most powerful acts of criticism, resistance, and defiance comes from those who have been designated as the 'lesser' of the dichotomies who then embrace and empower that definition, using it as the starting point of their resistance" (Hahm 2000, 103).
} 
or informally institutionalized discourse, which represents a psychological foundation and a central approach of Orientalism, is simply a form of ethnocentrism, one among many others. Orientalism functions by applying Eurocentric views and validations of reality. And because Orientalism is a discourse of power, Eurocentrism naturally forms a part of the same power. In a certain sense, they are simply two sides of the same medal. It is precisely this fact which makes Eurocentrism something more influential than most of other ethnocentrisms - the fact that it is an ethnocentrism based upon a "higher" position of economic and political supremacy, which is a result of specific social, ideational and historical developments. And what is especially important for our present discussion is also the fact that in a wider sense, i.e. in terms of everyday life, Eurocentrism is no longer limited to Europe, but represents a contemporary, global phenomenon. ${ }^{4}$

Similar to the ways in which Eurocentrism hence is posited against other forms of ethnocentrisms, like Islamocentrism or Sinocentrism, Orientalism is posited against Occidentalism, ${ }^{5}$ which is also a discourse representing the "Eastern", African and Muslim worlds as the "Others," often in equally dehumanizing and ideological way as Orientalism. It can also be seen as a form of nationalist essentialism in the non-European or non-Western world, especially in Asia, which is increasingly redrawing the global map of economic development. Here again, however, the difference between both discourses is (similar to the relation between Eurocentrism and, for instance, Sinocentrism) in the abovementioned global power relations, which are deeply rooted in historical and axiological conditions laid by the colonial and post-colonial world.

However, Occidentalism cannot be mixed up with a phenomenon denoted as "reversed Orientalism" or "Orientalism in Reverse," which is rooted in conditions established by the "leading historical role" 6 of Orientalism. One of the most significant features of this discourse can be found in the presumption, according to which there exists a fundamental ontological difference between the natures of the "East" and the "West," i.e. between the so-called Eastern and Western societies, cultures and even peoples.

This ontological difference entails immediately an epistemological one which holds that the sort of conceptual instruments, scientific categories, sociological concepts, political descriptions and ideological distinctions employed to understand and deal with Western societies remain, in principle, irrelevant and inapplicable to Eastern ones (al-Azm 1980, 10).

4 This holds true for general evaluations of many crucial values, the structuring of social relations, aesthetic concepts and political or economic systems. Regarding the central subject of this study, i.e. the research in Chinese social and conceptual theory, this phenomenon can clearly be observed in the way many Chinese scholars are dealing with (and interpreting) the classical sources - namely throughout through the lens of European (or "Western") methodological premises.

5 Mohammed Chabi explains the difference between the two notions as follows: "If Orientalism was the creation of the center, then Occidentalism is the creation of the periphery. By this I mean that Orientalism was created by the "great states" of the West in order to achieve their objectives; whereas Occidentalism is created by an oriental élite working and living in the West and became lured by its principles and values. So, Occidentalism depends on Empiricism that is to say experience because they live and work in the place of study; whereas Orientalism calls for Rationalism that is shaping the values and beliefs of others to their reason." (Chabi 2012,3)

6 This "leading historical role" is, of course, limited to the periods of renaissance, the industrial and the Copernican revolution. 
In such a view, differences between "Western and Eastern" societies are not so much a result of complex processes in the historical development of humanity, nor "a matter of empirical facts to be acknowledged and dealt with accordingly" (ibid.). In addition to all that, they are first and foremost products of a certain "Oriental essence," pertaining to the cultural, psychic or racial nature of the non-Western "Others." Sadiq Jalal al-Azm denotes this form of discourse Ontological Orientalism (ibid.). Orientalism in this sense provided a fertile basis for the establishment and development of the Reversed Orientalism, which manifests itself primarily on the epistemological level. It assumes, for instance, that "only Japanese can understand Japan, only Chinese can understand China” (Lary 2006, 9).

Even the very notion of Orientalism was not unproblematic after it was published in the regions belonging to the so-called "Orient": Said's book was welcomed by people who understood its main message; however, by many other scholars, Said views were also sharply criticized. His arguments that "the Orient" had been diminished and distorted by Western specialists were especially irately rejected by numerous Chinese scholars and intellectuals. (e.g. Zhang 2020, 2016-18; Yao 2019, 210; Zheng and Chen 2019, 235-6)

Moreover: No matter how well versed Western sinologists are in Chinese language and culture, in such a view they can simply never understand Chinese culture. Diana Lary provides a good illustration for such an attitude:

One example is research on Peking Man, who may or may not have been the ancestor of the present-day Chinese. The fossil remains of Peking Man were discovered in the late 1920s by an extraordinary team of scholars that included Chinese (Pei Wenzhong) and foreigners (the Swede J. G. Anderrson, the French Pierre Teilhard de Chardin, and the Canadian Davidson Black). A young Chinese archaeologist who discussed the discovery with me in 2005 would only accept the role of Pei; the Western scholars were dismissed as having done next to nothing. In this view he was following a fairly common convention in Chinese scholarship that Westerners have made little impact on the study of China. There is a similar unwillingness to give any credit for the discovery a little earlier of the Oracle Bones, the first form of Chinese script, to the Canadian missionary James Menzies (ibid.).

John Timothy Wixted provided us with another illustrative example of Reversed Orientalism in the field of epistemology:

The expectation on the part of many Chinese is that work on China by non-Chinese is no good. If, however, it is clear that the work is good, then the reaction, which on occasion I have witnessed, can be this: I, as a Chinese, am ashamed, am humiliated, that this work was not done by a Chinese. I have heard Chinese say this (and mean it) about the Takigawa Kametaro's edition of the Shih-chi and certain other Japanese scholarship, about Kalgren's work on Chinese phonology, and even about a volume of my own work. This self-inflicted psychological pain tells us something, I believe, about an aspect of Chinese Reverse Orientalism: many Chinese, in a possessive, exclusionist, self-contained way, consider the study of China their bailiwick and theirs alone; and the inward centeredness of this Chinese cultural world prevents such Chinese from taking active pleasure either in the scholarship itself, in the fact that others are doing work that can redound to the benefit of Chinese and non-Chinese Sinologists alike, or in the fact that such work might increase appreciation of the richness of Chinese culture among non-Chinese (Wixted 1989, 22). 
However, we should not pour out the baby together with the bathing water. Firstly, this situation has much improved during the last decade: the Chinese academic world has become increasingly aware of the contributions of Western sinologists and experts in Chinese studies to the spreading and deepening of knowledge on Chinese culture and society in the Euro-American worlds. On the other hand, the majority of Chinese scholars (and policy makers) has obviously recognized that some issues can be better investigated from a certain distance; and furthermore, they would certainly like maintain a stronger control over the Western academic production on their country. Because of all these reasons, a huge deluge of books and articles on Western perception and interpretation of China has been (and is still being) translated into Chinese and published by various Chinese publishing houses and journals.

Secondly, we should - as Diana Lary points out - not take the above described Sinocentric academic biases too serious. First of all, even those Chinese people who are holding such views are willing to acknowledge that individual Western scholars can be quite capable. Such people are usually honored with the label “Zhongguo tong 中国通”, a colloquial and populistic expression which means that a foreigner has gained a profound and genuine insight into Chinese language and culture. On the other hand, Lary also rightly emphasizes that the basic problem of the Reversed Orientalism is linked to much more general and elementary issues regarding representation and appropriation within the historically developed inequalities:

Can men write about women, can white people write about blacks? These are concerns that are deeply felt, and that can never be easily resolved, since they are based on perceptions of long-running discrimination and misrepresentation. (Lary 2006, 9).

If we truly want to begin placing, observing and explaining Chinese texts in the historical, linguistic and methodological context to which it belongs, we cannot ignore the specific processes of global interactions which demarcate its present state. Hence, in this endeavor we have to consider the historical role and the impact of power structures and the consequent establishment of privileged and underprivileged or even discriminated social groups and cultures. On the other hand, however, we have to watch out not to slip into a hole of opposite prejudices. We also have to be aware of the fact that in spite of this principal socio-cultural inequalities, of which the European past (and present) is certainly a great part, we need to think through a dialectical interplay between aids and wrongdoings, for "Europe does and has made great contributions to humanity, just as crimes have been committed against humanity in the name of Europe" (West 1993, 148). I cannot but strongly agree with Cornel West who emphasizes (ibid.) that in order to surpass and to go beyond Eurocentrism and multiculturalism, we have to begin reflecting upon these issues in a much more complex way, which includes a nuanced historical sense, a subtle social analysis and, above all, a radical democratic worldview, i.e. a worldview which allows for equal rights of all cultures and societies. 


\section{The hybrid nature of sinology}

The postcolonial view on recent historical developments in the field of Chinese studies still didn't manage to effectively separate themselves from essentialist and orientalist understandings of contemporary Chinese society. The recent omnipresence of China in all types of media is still not accorded by its place in intellectual and academic production or expertise (Vukovich 2010, 148). Sinology has been - theoretically and methodologically - accused of unreflectingly repeating the wrongdoings and sins of its colonial and orientalist past. In the neo-liberal presence, the vast knowledge and profound understanding that the Chinese language and its humanistic tradition have to offer are not only seen as being redundant, but often (as many other potentially critical discourses) even as dangerous and hence unwanted. In recent years, most universities have replaced sinology by empirical Chinese studies, which are primarily oriented towards modern and contemporary China and more or less ignoring the richness and the latent, subtle, but sublime impact of its past. Most Western governments have drawn exclusively on information "supplied by 'experts' who, more often than not, are woefully lacking in knowledge of the history, languages, literatures, and customs of the countries they speak about" (Wixted 1989, 25).

Sinology, on the other hand, has hitherto still not solved most of the elementary problems connected to its "hybrid nature." This problem is different and has to be treated separately from the (equally difficult and complex) problem of its Orientalist roots, which causes that numerous scholars both inside and outside China, taking their cue from Said, still believe that Sinology is a form of Orientalism (Gu 2013, 43). In his passionate attack against sinology as an academic discipline, Hans Kuijper dismisses sinologists as pseudo-scientists, for in his view, they are lacking any form of sinological theory (Kuijper 2014,151 ). He also thinks that sinology is wrongly defined (namely by the object of its inquiry instead of by the optique on this object) and is not a systematic study (Kuijper $2000,338)$. He is convinced that sinologists

do not see the nexus, or Gestalt (configuration), of the object of their study (China), the relationships between, or specific combination of, its elements or subsystems, the whole that is different from the sum of its numerous parts. ... They do not know how China, as an extremely complex unity, works; they do not comprehend its wiring, its deep structure and dynamics. Not seeking to "uncover" and understand the orderliness of China qua China, they disqualify as scientists. Indeed, the emperor is wearing no clothes (ibid.).

However, Kuijper also offers a solution to this problem he; proposes to the sinologists either to devote their careers to the project of translating the vast number of important works of Chinese culture that have still not been made available to the Western audience, or to collaborate in those fields of Chinese studies, in which they are interested, with (real) scholars of parallel Western disciplines, because the latter do possess a theory and a specific research methodology.

Notwithstanding Kuijper's well intended advices, it is certainly not necessary to emphasize that not everybody could agree with his assumptions - at least, of course, those sinologists who have gained an international reputation as brilliant theoreticians. 
Hence, it is not surprising that according to Denis Twitchett, a renowned sinologist and expert for Chinese history, ${ }^{7}$ sinology has "far more unity, a more closely integrated set of techniques, and far more of a corporate sense of purpose than has, for example, history" (ibid., 109).

It is doubtless true that in its Orientalistic past, (the relicts of which often spooked around even in some of the most distinguished Western departments of sinology until the beginning of the present century) sinologists were seen as a kind of experts for everything regarding China. ${ }^{8}$ Nowadays, the only common point that all sinologists (should) possess, is their mastering of modern and classical Chinese language and the kind of general education regarding Chinese culture that has to be retained by an average Chinese high school graduate. In the course of their studies, Western students of sinology have thus to obtain at least the basic knowledge of Chinese political, socio-cultural and ideational history; they have to be acquainted with the main developmental trends and paradigms in Chinese literature, art and philosophy. French students of German studies, for instance, must not learn German philosophy or sociology in the course of their study. But in sinology, such subjects necessarily have to be a part of the obligatory curriculum, simply due to the fact, that European (or Western) students don't learn almost anything about Chinese history, culture and society during their high school education.

That is to say, Sinology should provide us with a broad understanding of Chinese culture and society in all its aspects, to give us the sort of instinctive understanding and orientation which we have of our own society simply by being born and educated in it. Moreover, it should give us the ability to see through the eyes of the Chinese literati who wrote our materials, and thus to enable us to discount their prejudices and preoccupations before reinterpreting what they have written in terms of our own (Twitchett 1964, 111).

This kind of general education is necessary even for those students, whose main interest is "only" the Chinese language and translations, and are therefore mainly interested in a linguistic training, for language is always an important and constitutive part of any culture.

However, sinologists who develop a special academic interest in any of the more specialized fields (e.g. Chinese history, sociology, philosophy, art, anthropology, law, etc.) have to go through a focused academic training in the respective discipline before they can become experts in the corresponding filed. This is not an easy task, because it requires professional training in both Chinese and Western academia. Here, we have to consider the fact that academic teachers in individual sinology departments can offer a specialized academic training only in their own filed of research. Hence, the sinological curricula in various departments differ from each other to a greater extent than most of the curricula

Twitchett (1925-2006) was a well-known British sinologist. He was a renewed scholar, specialized in Chinese history and is famous as one of the authors and editors of the Cambridge History of China.

8 At the other extreme, the term sinologist is also often used to characterize a rather ridiculous caricature compounded of pedantry and a preoccupation with peripheral and precious subjects of little general significance. However, Denis Twitchett, rightly reminds us that the pedantry and the preoccupation with trivia are by no means monopolies of the Sinologist: "A glance through current issues of journals concerned with Western history or the social sciences on the shelves of any library would lead one to suppose that a vigorous training in one of the disciplines is no more prophylactic against the misemployment of advanced techniques of analysis in the pursuit of unimportant topics" (Twichett 1964, 110). 
in other disciplines. In the ideal instance (which is often the case), future sinologists can combine their study with another discipline - and most often it is the same field as the one they want to specialize in within sinology.

But in strictly methodological sense, such an "ideal" combination is not as trouble-free as it seems to be at the first glance especially in those cases, in which the field of sinological specialization is being learned solely in one of the general (i.e. non-sinological) departments. As we shall see in later parts of this book, the optique of Western methodological systems does not always apply to the study of Chinese tradition. On the contrary, sometimes it can be quite disturbing. Academic methodology is namely (at least in the fields of social sciences and humanities) always implying a certain kind of viewing and interpreting reality. In Western humanities, these discrete approaches to reality are results of specific (i.e. Western) historical and ideational developments. Such methodologies provide us with a systematic set of categories and concepts; it furnishes us with a setting of methods and with a series of referential frameworks. These are necessary and essential elements of any theory. However, while the specific methodologies that were created in particular disciplines can offer us a special tool to work with, it is precisely the very same tool that simultaneously limits our treatment of the selected subject matter, if it pertains to a different language and culture. If we namely internalize this particular view of reality, we might overlook numerous, often significant, elements that can only manifest themselves when observed from a different viewpoint which lies beyond the methodological framework we are using, because it is embedded in different paradigms of perceiving, understanding and interpreting reality.

As already mentioned, concepts, categories and methods of inquiry cannot be automatically transferred from one socio-cultural or linguistic area into another. This becomes even more visible if the two areas in question are separated by significant differences in linguistic, grammatical and semantic structures, by large spatial distances and by diverse trajectories of historical and socio-cultural developments.

Nowadays, it is a long known fact that applying terms and classifications deriving from Western social sciences or Western economic-political theory to the histories and present situations in non-Western societies and cultural areas can be seriously misleading. Even today, several Chinese (and even Western) theoreticians who work with Western sociological categories in an uncritical way, still denote all ancient, medieval and pre-modern developmental periods of the Chinese societies with the term "feudalism," although the modes and structures of production were completely different throughout the Chinese and European histories respectively. ${ }^{9}$ The non-European modes of production were

9 If at all, the term "feudalism" applies in China solely for the Western Zhou period (1066-771 BCE). In Europe, feudalism was determined by the hierarchical relationships between different positions within the nobility, and by the farmers and workers (villeins) who invested their physical labor by which they supported the entire social structure, a part of which were also influential religious leaders. Nobility titles, as well as the position of the villeins were hereditary, which means that the latter were dependent serfs with respect to their lord. In China, on the other hand, the peasants who cultivated the land of the owners, who belonged to the gentry, were basically free to leave. The system was controlled by the bureaucracy class; the positions within this class were not hereditary. Instead, they were based on a form of "meritocracy," i.e. the official examination system. In translating the Western term "feudalism" into their language, the Chinese translators have applied the term “fengjian 封建," which was originally a Confucian and Legalist notion describing a decentralized system of government during the Zhou dynasty, based on four elementary occupations. To increase the confusion, the 
always seen as a kind of deviation from the norm - thus, for instance, the establishment of the term "Asiatic mode of production" along with all its utterly negative connotations. The same applies, for example, to the modernization theories and the role of non-European ideational traditions in these processes. (Rošker 2016, 9-23) Without a detailed and in depth sinological research, the clarification of such Eurocentric "misunderstandings" in social sciences would not be possible.

The same goes for most of the disciplines and research fields within humanities. In making history, experts of this discipline cannot surpass difficulties related with discursive representations, simply due to the fact that constructing and writing history as such is necessarily a process of representation grounded upon a discourse. Regarding the writing and the evaluation of Chinese history, sinology and the issues it highlights, are substantial in helping historians become more conscious of the problematic nature of history and historiography, and hence more critical to the discourse in which they are working and from which they are a part. It is sinological knowledge that allows them to understand how and why understanding is being standardized, "normalized" and Westernized, and to see the implications of such knowledge for the construction of history (Mittal 2015, 1). It is namely by no means sufficient to simply re-place this discourse into the framework of post-colonialism, because this field of research and writing still structures the non-Western problems in the very framework of Western axiology and methodology.

This problem is also well-known in the field of comparative literature. Many Western sinology trained experts in Chinese literature emphasize the fact that Chinese literature is not well-served by Western generic classifications. The treatments of non-Western literatures through the lens of the criteria established by Western formal, technical, structural and narrative approaches still remain rooted in Eurocentric assumptions. However, these have to be critically questioned:

Assumptions are a natural and necessary way of extrapolating and applying information, but it ought to be salutary to examine the ways in which

1) Chinese literature is not, and perhaps cannot be, represented by wholly equivalent terminology when treated in non-Chinese languages, and

2) Chinese literature is treated as forming a coherent and national whole, and whether this accurately reflects the scope of sinophone writing (Stenberg 2014, 287).

Josh Stenberg critically questions such a genre universalism by highlighting that it is still reasonable to ask whether French roman and the English novel were "the same thing" (ibid.), or whether the novel as such is a definable unit at all. It is certainly true, however, that they were at least conceived and developed with knowledge of each other and thus with a certain sense of equivalence, while also having common areas of reference. None of this applies to the Chinese “novel” (i.e. xiaoshuo 小説). “This same concern should run through all of the equivalences made between the European generic terms - poetry, biography, prose, perhaps especially drama" (ibid., 288) and independent traditions with their own names and histories. The same holds true for the classification of literary

Chinese version of Marxism has (in order to ensure that China also fitted into the "norm," i.e. into the Marxist classification of particular stages of social development) defined the entire traditional and pre-modern period of Chinese social history as a form of "feudalism." 
currents, movements or styles, because literary works always represent different cultural conditioned interpretations of social problems, connected to different intellectual histories, moral philosophies, social criticism, aesthetic formations and other fields of reasoning which are of relevance to the way humans interpret meaning.

It is certainly not a coincidence that Lu Xun, for instance, has often been named "the Chinese Gorki" by literary criticism. But nevertheless, the reality from which Lu Xun's "madman" is escaping and which he fears to death, the reality which swallows lives and destroys destinies of all his characters, is completely different from the one from which Gorki's heroes are fleeing and in which they have been helplessly thrown. Not only sinological, but also literary comparatists and theoreticians should always be reminded of such facts, because they still tend to excessively press the creative work of "other" cultures artists into the molds of Western methodological classifications. Therefore, the great works of Chinese literature should not be read through the optics of Eurocentric categories of the traditional "World literature," which primarily referred to the masterpieces of Western European literature, because such a reading necessarily transforms them into weak versions of this allegedly "universal" discourse. (Pizer 2006, 32-9)

Perhaps the illiteracy regarding differently structured principles for creating literary or artistic products becomes most visible in the example of traditional Chinese poetry. In their work, almost no traditional Western translator has tried to maintain the very strict metric principles typical of classical Chinese poetry. This kind of ignorance has led to certain prejudices, which underlie most of the public perceptions of traditional Chinese lyrics in Western regions. Chief among these is the false assumption that they belong to a highly "modernistic" style of poetry, based on pure association, and written in a free verse style, without any restrictions regarding rhythm, rhymes, or other prosody or versification instructions. This, of course, is again a completely wrong view, because, as every sinologist knows, most of the traditional Chinese poetry was created under application and consideration of very strict and complex metrical rules. (Rošker 2014, 26; see also Lomova 2018, 70)

\section{Textual criticism and discursive translations}

All these questions point to the fact that comparative views in any of the disciplines are difficult and much more complex than it seems at a first glance. However, sinology is - in its essence - a discipline that stands and comes into action in any serious comparison or communication between any aspect of Chinese and Western cultures. In its nature, it is a bridge, connecting different cultural, historical and ideational heritages by introducing and interpreting one to another. And in its specific discourse, which is defined by transitions and by fusions of different cultural, ideational and linguistic spheres, it developed very specific, and relatively coherent, disciplinary methods. The common thread or the general basis of all these methods manifests itself in the methodological framework of a vigorous textual and philological criticism, which necessarily underlies any kind of historically conscious research investigating China and its multifarious cultures. Textual criticism is the analysis and the interpretation of texts via their semantical, syntactical, historical, and cultural contexts. Questions about the life of the author, the way the 
author's use of language fits in with the text's time period, and so on, are also part of textual criticism (Creeler 2014, 201. See also Shun 2009, 458).

As an interpretative and analytical discipline, sinology necessarily includes translations - however, not merely direct translations of a wide opus of classical Chinese works, as advised by Hans Kuijper. Of course, systematic and exhaustive translations of all important classical works which shaped the Chinese intellectual tradition doubtless also belongs to the most important tasks for those sinologists who are specialized in Chinese linguistics and trained in the translation theories. However, what I have in mind, is clearly not limited to merely rendering one language into another, but also involves the "translation" or transposition of different discourses. This form of "translation" is often taking place merely on the abstract level of reasoning and must not necessary be written down let alone published. It is an essential part of every sinological research and involves interpretations of individual textual and speech structures, categories, concepts and values that differ depending on their socio-cultural contexts. In the process of such work which is relies on both analytical as well as hermeneutic methods, sinologists often encounter a discrepancy between the etymological and the functional understanding of a given expression. In some cases, the same notion may even be understood completely differently, depending on the general social context of the two different societies in which it appears.

To illustrate this point, I shall shortly explain the results of an intercultural socio-linguistic investigation (Rošker 1995, and Rošker 2012), which I conducted in Taiwan and partly (for the sake of the comparative perspective) in Central Europe in 1995. The study included inspection and comparison of several different dictionaries and encyclopedias, textual analyses as well as contrastive proportional surveys in Central Europe and in Taiwan. ${ }^{10}$ The results of the inquiry clearly exposed that the common understanding of the word autonomy in the Central European cultural and linguistic context is closely connected to the notion of freedom in the sense of non-interference. The general perception of its official synonym in the Chinese language (zilü 自律), on the other hand, proved to be mainly linked to the semantic complex of "self-restriction" in the sense of self-control and self-discipline respectively. ${ }^{11}$ These two kinds of comprehension are not only different, but also mutually contradictive, although the etymological meaning of both terms (autonomy and zilü respectively) is more or less the same, both implying concepts as "self-law" or "self-regulation" and phrases like "to decide one's own law" or "to establish the law (or regulations) by oneself." The research results have shown that this discrepancy derives from different understandings of the notion law ${ }^{12}$ and its respective traditional connotations in both cultures in question. In Europe, the law was established

10 The informers were 2nd grade students of the Educational sciences at the universities in Vienna (50), Ljubljana (50) and Hsinchu (103).

$1191 \%$ of the European informants described the notion of autonomy with terms such as "independence", "self-dependence", "self-determination" and "freedom", i.e. with words belonging to the semantic scope of a condition without any external limitations or impacts. On the other hand, over $88 \%$ of the Chinese informants have described the meaning of the term 自律 with notions pertaining to the scope of self - conscious consideration of rules or limitations, such as self-restriction (自我约束)”, “self-control (自我控制)”, or “self-discipline (自我纪律)" (Rošker 2012, 33-34).

12 Which were, of course, rooted in the different social functions of law in the Chinese and the European societies. 
in order to protect individuals (and their property) from the violence and heteronomy of the others; hence, it included both, the restrictive, but also the protective function. The latter was closely associated with freedom, because only a safe person could afford to be free. The person with the greatest amount or degree of freedom was, according to such a logic, the person who had the power to establish the law by oneself. In China, on the other hand, law was never (with a tiny exception of the Qin 秦dynasty rule, which lasted 15 years) seen as the main means for regulating human relationships and it was mainly associated with restrictions, prohibitions and punishments. Hence, to establish a law for and by oneself could only imply self-restriction or self-discipline. These connotations are still reflected in the general understanding of the Indo-European notions of word autonomy, and in the Chinese term zilü which was - according to most dictionaries - often used as its synonym.

A broader socio-semantic investigation, which was conducted subsequently, has namely clearly shown that the European term law and its Chinese synonym $f a$ 法 have the same format and functional meaning; yet their mutual difference arises only from their particular cultural connotations. Although such inquiries might seem redundant, because they seemingly focus upon some trivial and unimportant terminological issues, they can have significant discrete consequences. When an average Chinese person speaks about autonomy, the concept she has in mind is something completely different from what an average Austrian person has in mind when mentioning the same term. If they speak with each other about autonomy, they will therefore often speak about two different things. This is only one small example for illustrating the fact that in-depth sinological research and discursive translation is significant not only for classical studies, but also for understanding contemporary China. It also shows that often - especially if we are dealing with conceptually complex texts and/or abstract theoretical discourses - a mere literal translation cannot provide a suitable tool for rendering meanings between different cultures. This inadequacy becomes even more apparent when we translate texts that originated in two different cultural areas that are as far apart historically, traditionally, and linguistically as China and Europe. In such case, we rather apply the method of discursive translations (Robins 1994, 406; Hadley 2017, 2; Acosta 2019, 10), which cannot be limited to a linguistic word for word transfer but must include the interpretation of specific textual/speech structures, categories, concepts and values existing in diverse socio-cultural contexts. In the context of the above example, our translation of the Chinese word zilü could not remain limited to one word, but should also include a short illumination of its specific conceptual background. The same applies for many concepts and categories of Chinese philosophy, which have no precise synonyms in Western languages and which are often translated with false (or at least misleading) terms, such as, for instance $l i$ 理, $q i$ 氣, jingjie 境界, dao 道, etc. However, this does by no means imply the elimination of positivist philological research. On the contrary: although nowadays, such approaches have often been seen as outdated and obsolete, a solid and objective philological knowledge is a necessary precondition for any serious discursive translation. Only if we can contemplate upon every single word and carefully consider style and formal aspects of the translation, we will become able "to present the original as an intelligible, yet alien text open to the scrutiny of (our) readers and to possible further dialogues about its meaning" (Lomova 2018, 81). 
In recent years, there has been a growing demand to revive the classic categories and concepts of traditional Chinese sources. This approach, however, involves the transcultural relativization of the contents based on methodologies that correspond to the specific requirements of research in the Chinese ideational tradition, and comparative philosophy or cultural studies in general. The priority in this approach is preserving traditional Chinese philosophical characteristics and maintaining autochthonous and traditional methodological principles. However, this does not mean denying or excluding an intellectual confrontation with Western (and global) philosophical systems. Global (especially European and Indian) philosophy includes numerous elements that cannot be found in the Chinese tradition. The investigation and application of these elements is not only a valuable means for fertilizing new idea systems, but also offers an important comparative tool for better understanding one's own tradition. At the same time, as the modern Chinese theorist Zhang Dainian ${ }^{13}$ cautioned, we must avoid the use of incompatible or incommensurable methods that attempt to study Chinese history through the lens of Western concepts and categories: "Different philosophical theories use different concepts and categories. Concepts and categories used in philosophical theories can differ greatly from one nation to another" (Zhang Dainian 2003, 118). ${ }^{14}$

As a final point, we must also take into account the differences between the original Chinese notions and their semantic connotations that originate in the translations of these notions into Indo-European languages. The expression “ $r u$ xue 儒學”, for instance, is commonly translated as "Confucianism" (also in the compounds as "New," "Contemporary" or "Modern Confucianism"). ${ }^{15}$ Thus, it automatically connotes Confucius (Kong fuzi $)^{16}$ and the various historical phases of the Confucian teachings. But "ru xue" actually signifies "the teachings of the scholars," ${ }^{17}$ which means that this expression does not a-priori exclude any of the major influences on the history of Chinese thought. In fact, this idea of traditional Chinese philosophy as the "teachings of the scholars" has been shared by most traditional discourses or lines of thought. ${ }^{18}$

13 張岱年.

14 不同的哲學理論包涵不同的概念, 範疇. 不同的民族的哲學理論, 更是具有不同的概念, 範疇.

15 During the last decade, the term "Ruism" as a new translation for "ru xue" also became increasingly common in Western Sinology.

16 孔夫子.

17 Numerous sinologists have noted the wider connotational scope of the term ruxue 儒學. Roger Ames, for example, has shown how this notion refers to a general classical "scholarly tradition" (see Ames 2011, 5). This, of course, does not mean that Daoist and Buddhist texts were included in the Confucian canon, but only confirms how inextricably intertwined these three major idea systems were. In most forms of Confucian state orthodoxy, e.g. the Shiji 史記and Hanshu 漢書, the term Ru 儒basically signifies an expert in the Five Classics. In her book on Confucianism and women, Li-Hsiang Lisa Rosenlee also writes: “The concept of $\mathrm{Ru}$ 儒... denotes the inexact Chinese counterpart of the term Confucianism used by Jesuits in the 18th century... The ambiguity of its semantic origins in ancient, pre-Confucian times obscures the connection between $\mathrm{Ru}$ as an intellectual discipline and Confucius, as its most prominent spokeperson. Unlike the term Confucianism - its secularized and simplified representation in the West - the complex term $\mathrm{Ru}$ can only be approximated as the teaching of the sages and the worthies wherein the ethical teaching of Confucius - the Supreme sage and the First teacher - forms a part, but an important part nevertheless" (Rosenlee 2006, 4).

18 In considering specific features of traditional Chinese philosophy that are common to all schools of ancient and classical Chinese thought, of primary importance are the concept of transcendence in immanence (or immanent transcendence), binary structured holism which functions by means of binary categories (for example yin-yang, you-wu, ti-yong, ming-shi etc), as well as the principle of complementarity which represents the method of interactions between both implied antipodes. 
In sinology - and in any branch of Chinese studies, textual criticism and discursive translations belong to reliable and comprehensive methods, which, of course, can only be applied after a long-lasting process of acquiring a wide, profound and detailed sinological education. They are elementary methodological paradigms for sinology and Chinese studies as academic disciplines, paradigms, which enable us to skillfully navigate and find our safe way between the Scylla of essentialism and Charybdis of evolutionism.

\section{Acknowledgement}

The author acknowledges the financial support from the Slovenian Research Agency (ARRS) in the framework of the research core funding Asian Languages and Cultures (P6-0243) and in the scope of the research project N6-0161 (Complementary scheme) Humanism in Intercultural Perspective: Europe and China.

\section{BIBLIOGRAPHY}

Acosta, Mariola, et al. (2019). "Discursive translations of gender mainstreaming norms: The case of agricultural and climate change policies in Uganda”. Women's Studies International Forum, 74:4, 9-19.

Al-Azm, Sadiq Jalal (1980). “Orientalism and Orientalism in Reverse." In: Europe Solidaire Sans Frontiéres. http://www.europe-solidaire.org/spip.php?article20360.

Ames, Roger T. (2011). Confucian Role Ethics: A Vocabulary. Honolulu: University of Hawaii Press.

Chabi, Mohammed (2012). “Orientalism Vs Occidentalism”. Morocco World News, 05.11.2012. https://www .moroccoworldnews.com/2012/11/63750/orientalism-vs-occidentalism/. Accessed: 28.01.2021.

Creller, Aaron (2014). Making Space for Knowing: A Capacious Alternative to Propositional Knowledge. Ph.D Dissertation. Honolulu: University of Hawaii at Manoa.

Dai, Yuanfang, ed. (2020). Transcultural Feminist Philosophy: Rethinking Difference and Solidarity Through Chinese-American Encounters. Lanham: Lexington Books.

Fredericks, James (1988). “The Kyoto School: Modern Buddhist Philosophy and the Search for a Transcultural Theology." Horizons 15:2, 299-315.

Gu, Ming Dong (2013). Sinologism: An Alternative to Orientalism and Postcolonialism. New York: Routledge.

Hahm, Chaibong (2000). "How the East was Won: Orientalism and the New Confucian Discourse in East Asia." Development and Society 29:1, 97-109.

Hadley, James (2017). "Indirect translation and discursive identity: Proposing the concatenation effect hypothesis”. Translation Studies 10:2, 183-97.

Heubel, Fabian (2020). "Within the Spinning Stillness of the Present". Asian Studies 8:3, 211-30.

Kuijper, Hans (2000). "Is Sinology a Science?” China Report 36:3, 331-54.

Kuijper, Hans (2014). "What's Wrong With the Study of China/Countries". Asian Studies, 2:1, 151-85.

Lary, Diana (2006). "Edward Said: Orientalism and Occidentalism.” Journal of the Canadian Historical Association / Revue de la Société historique du Canada 17:2, 3-15.

Lee, Ming-Huei (2013). Konfuzianischer Humanismus - Transkulturelle Kontexte. Bielefeld: Transcript Verlag.

Lomova, Olga (2018). "Oriental Philology in the Service of Bettering Man: Rudolf Dvořák’s Czech Translation of the Daodejing”. Studia Orientalia Slovaca, 17:1, 65-83.

Mittal, Ayesha (2015). "Eurocentric Criticism: The Problem with 'Orientalism' and Post-Colonial Theory." Ayesha Mittal Writes: Pop Culture, History and Politics through a Feminist and Racial Lens website, https://amittalwrites.wordpress.com/2015/04/13/eurocentric-criticism-the-problem-with-orientalism -and-post-colonial-theory/. Accessed 06.02., 2019.

Nielsen, Greg (1995). “Bakhtin and Habermas: Toward a Transcultural Ethics.” Theory and Society 24:6, 803-35. 
Nelson, Eric S. (2020). "Zhang Junmai's Early Political Philosophy and the Paradoxes of Chinese Modernity". Asian Studies 8:1, 183-208.

Ongun, Ömer (2016). "From Interculturalism to Transculturality: The Puzzling Form of Cultures Today." Intercultural learning website. http://ectp.eu/efillife/?p=1816. Accessed: 28.01.2021.

Pizer, John (2006). The Idea of World Literature: History and Pedagogical Practice. Baton Rouge: Louisiana State University Press.

Robyns, Clem (1994). “Translation and Discursive Identity." Poetics Today 15:3, 405-428.

Rosenlee, Li-Hsiang Lisa (2006). Confucianism and Women: A Philosophical Interpretation. New York: State University of New York Press.

Rošker, Jana S. (1995). "Intercultural Comparative Survey on the Understanding of the Concept Autonomy". (Questionary 12.11.1995). Hsinchu: National Hsinchu University of Education.

Rošker, Jana S. (2012). "Cultural Conditionality of Comprehension: The Perception of Autonomy in China." In: Reinventing Identities: The Poetics of Language Use in Contemporary China, edited by Tian Hailong 田海龍, Cao Qing 曹清, et al., Tianjin: Nankai daxue chuban she. 26-42.

Rošker, Jana S. (2014): "Introduction". In: The Hermit: Classical Chinese Lyrics in Slovene, English and German translation. Ljubljana: Znanstvena založba FF. 24-31.

Rošker, Jana S. (2016). The Rebirth of The Moral Self: The Second Generation Of The Modern Confucians and Their Modernization Discourses. Hong Kong, Honolulu: Chinese University Press and University of Hawaii Press.

Rüssen, Jörn (2004). "How to Overcome Eurocentrism? Approaches to a Culture of Recognition by History in the 21st Century." Taiwan Journal of East Asian Studies, June 2004: 59-74.

Said, Edward W. (1978). Orientalism. New York: Pantheon Books.

Shun, Kwong-loi (2009). "Studying Confucian and Comparative Ethics: Methodological Reflections." Journal of Chinese Philosophy 36:3, 455-78.

Siegel, Harvey (1999). "Multiculturalism and the Possibility of Transcultural Educational and Philosophical Ideals." Philosophy 74:3, 387-409.

Silius, Vytis (2020). "Diversifying Academic Philosophy." Asian Studies 8 (2): 257-80.

Stenberg, Josh (2014). "Two Questions about Categories in the Relationship of Chinese Literature to World Literature." Canadian Review of Comparative Literature / Revue Canadienne de Littérature Comparée 41:3, 287-303.

Twitchett, Denis (1964). "A Lone Cheer for Sinology." The Journal of Asian Studies 24:1, 109-12.

Valera, Eduardo Pérez J. (1972b). "Toward a Transcultural Philosophy (II)." Monumenta Nipponica 27:2, 175-89.

Vukovich, Daniel (2010). "China in Theory: the Orientalist Production of Knowledge in the Global Economy." Cultural Critique 2010 76, 148-72.

Welsch, Wolfgang (1999). "Transculturality-The Puzzling Form of Cultures Today." In: Mike Featherstone and Scott Lash (eds.), Spaces of Culture: City, Nation, World. London: Sage. 194-213.

West, Cornel (1993). "Lecture: Beyond Eurocentrism and Multiculturalism." Modern Philology 90 (Supplement): $144-51$.

Wixted, John Timothy (1989). "Reverse Orientalism." Sino-Japanese Studies 2:1, 17-27.

Yao, Dadui 姚达兑 (2019). “Dongfanzhuyi, hanxuezhuyi yu shijie wenxue lilun 东方主义、汉学主义与世 界文学理论” [Orientalism, Sinologism and the Global Literary Theory]. Zhongguo yuyan wenxue yanjiu, 2019 02, 210-217.

Zhang, Dainian 張岱年 (2003). Zhongguo zhexueshi fangfalun fafan 中國哲學史方法論發凡 [An Outline of the Methodology of the History of Chinese Philosophy]. Beijing: Zhonghua shuju.

Zhang Moyan 张墨研 (2020). »Weiwushiguande quanqiu shiye - bo hou zhiminzhuyi Makesi pipande sange jieduan 唯物史观的全球视野 - - 驳后殖民主义马克思批判的三个阶段 《 [Redrawing the global map The Global Vision of the Materialist Conception of History: Three Stages of Rebuttal to The Criticism of Marx from Postcolonialism]. Dangdai guowai Makesizhuyi pinglun 2020 02, 215-236.

Zheng Jiangtao郑江涛 and Chen Yan 陈艳 (2019). “Wenhua zixin yu Sayidede dongfangzhuyi 文化自信与 萨义德的东方主义” [Cultural self-confidence and Said's orientalism]. Dazhong wenyi, 2019 04, 235-236. 